\title{
The Psychological Impact of Six Weeks of Lockdown as a Consequence of COVID-19 and the Importance of Social Support: A Cross-Cultural Study Comparing Spanish and Russian Populations
}

\author{
Berta Ausín ${ }^{\mathrm{a}^{*}}$, Miguel Ángel Castellanos ${ }^{\mathrm{b}}$, Clara González-Sanguino ${ }^{\mathrm{a}}$, \\ Olga V. Vakhantseva ${ }^{c}$, Olga V. Almazovac, Ludmila A. Shaigerova ${ }^{c}$, \\ Aleksandra G. Dolgikhc, Manuel Muñoz ${ }^{\mathrm{a}, \mathrm{d}}$ \\ a School of Psychology, Personality, Evaluation, and Clinical Psychology Department, \\ Complutense University of Madrid, Spain \\ ${ }^{\mathrm{b}}$ School of Psychology, Psychobiology and Methodology in Behavioral Sciences Department, \\ Complutense University of Madrid, Spain \\ ${ }^{c}$ Faculty of Psychology, Lomonosov Moscow State University, Moscow, Russia \\ ${ }^{\mathrm{d}}$ Chair Against Stigma Grupo 5-Complutense University of Madrid, School of Psychology, \\ Complutense University of Madrid, Spain
}

*Corresponding author. E-mail: bausin@ucm.es

Background. The COVID-19 pandemic has been an unprecedented social and health emergency worldwide. Cross-cultural research on mental health during this situation is needed to better understand its consequences.

Objective. To evaluate the different psychological impacts of the crisis and lockdown situation during the first six weeks of COVID emergency measures in samples of the Spanish and Russian populations.

Design. A cross-sectional study was conducted through an online survey $\left(\mathrm{N}_{\text {Spain }}=1041 ; \mathrm{N}_{\text {Russia }}=743\right)$. The prevalence of loneliness, depression, anxiety, perceived discrimination (PD), internalized stigma (IS), and perceived social support (PSS) was evaluated. Chi-square tests and t-tests were administered. The Enter Method were used to identify the predictors of the mental health impact.

Results. Differences were found between the Russian and the Spanish populations. While the degrees of anxiety and depression did not differ significantly, loneliness, the alienation dimension of IS, and PD were more pronounced in the Russian respondents. In Spain, the predictor of less negative impact was PSS from various sources, while in Russia we only found PSS from the family.

Conclusion. Although in both countries the impact at the clinical level seemed to be similar, differences were found at the psychosocial level. Variables with a strong cultural component may be key to determining the means of alleviating the effects of the crisis, with PSS being a fundamental protective factor. More crosssectional studies are needed to understand the impact of the pandemic in depth.
Keywords:

COVID-19;

loneliness;

mental

health;

perceived

discrimina-

tion (PD);

internalized

stigma (IS);

perceived

social

support

(PSS) 


\section{Introduction}

The alarm generated by COVID-19 has turned into a social and health emergency with political measures and consequences of unprecedented scope throughout the world. In both Spain and Russia, governments have adopted strict confinement measures for the population.

On March 14, 2020 a state of emergency was declared in Spain, and drastic quarantine measures were established for all Spanish citizens. First, citizens were confined to their homes for two weeks, during which time it was only possible to leave home for essential activities (shopping or going to work). The second twoweek period was much more restrictive. From March 30 to April 12 there was a total suspension of all non-essential employment activity, which aggravated the already serious economic crisis.

On May 2, after seven weeks, the first steps were taken to partially lift the lockdown. The entire population was allowed to do contact-free sports or take a daily walk. They could be accompanied by only one person with whom they lived, or by a regular caregiver, and the activity had to be within a kilometer of their home. Two months after Spain began the lockdown, the pandemic began to recede, and in half the country the lockdown began to be lifted. After almost 100 days of confinement, Spain already had 246,752 cases, including 28,325 confirmed deaths and more than 150,376 recovered (Ministry of Health, 2020).

In Russia, COVID-19 first broke out on January 31, 2020. In February and March, the first containment measures were introduced by the state administration, with restrictions on the entry of foreign citizens and stateless persons into the country. In his address to the nation on March 25, the President of Russia announced a non-working period from March 30 to April 3 in order to fight the spread of the disease. On March 30, a self-isolation order and restrictions on the movements of Russian citizens were introduced. The order allowed citizens to leave their homes only for valid reasons (which differed slightly from region to region), such as essential workers traveling to work, or individuals going to a pharmacy or the nearest grocery store. Outdoor activities were forbidden for everyone, except for walking pets at no more than 100 meters from the place of residence. The mandatory distance of 1.5 meters between individuals and the mandatory wearing of masks and gloves in public places were also implemented.

As of the start of this study (May 11, 2020) 221,344 cases of coronavirus had been identified in 85 regions of the Russian Federation, according to Rospotrebnadzor (Federal Service for the Oversight of Consumer Protection and Welfare). By this time there were 2,009 registered COVID-19 deaths and 39,801 recoveries (Federal Service for the Oversight of Consumer Protection and Welfare, 2020). After two and a half months of confinement, on June 14, 2020, a gradual lifting of restrictions began. Thus, at the beginning of our study, the numbers of registered cases of infection in Spain and in Russia were approximately comparable, while the number of COVID-19 losses in Spain was 14 times higher than the number of deaths in Russia.

The impact on the population's mental health of pre-Covid-19 quarantines is established; however, there have been few large-scale studies providing significant evidence to account for the effects of quarantine, probably due to the uniqueness of each situation. 
In a recent review, Brooks et al. (2020) included 24 studies that addressed the negative effects of quarantine on mental health. Among the major diseases that have led to some form of quarantine in recent years are Severe Acute Respiratory Syndrome (SARS) and Ebola, although the length of the quarantine is unclear in several studies (Blendon, Benson, DesRoches, Raleigh, \& Taylor-Clark, 2004; Braunack-Mayer, Tooher, Collins, Street, \& Marshall, 2013; Caleo et al., 2018; Liu et al., 2012; Marjanovic, Greenglass, \& Coffey, 2007; Mihashi et al., 2009; Pan, Chang, \& Yu, 2005; Sprang \& Silman, 2013; Wu et al., 2009, n.d.; Yoon, Kim, Ko, \& Lee, 2016), and ranges from one week to 21 days in others (Bai et al., 2004; Cava, Fay, Beanlands, McCay, \& Wignall, 2005; Desclaux, Badji, Ndione, \& Sow, 2017; Hawryluck et al., 2004; Maunder et al., 2003; Pellecchia, Crestani, Decroo, Van den Bergh, \& Al-Kourdi, 2015; Robertson, Hershenfield, Grace, \& Stewart, 2004; Wang et al., 2011; Wester \& Giesecke, 2019; Wilken et al., 2017)

Various studies have indicated that quarantine is associated with increased psychological distress (Taylor, Agho, Stevens, \& Raphael, 2008); diagnostic symptoms of post-traumatic stress disorder (PTSD) (Reynolds et al., 2008); depression (Hawryluck et al., 2004); greater levels of stress (DiGiovanni, Conley, Chiu, \& Zaborski, 2004); insomnia, irritability, and low mood (Lee, Chan, Chau, Kwok, \& Kleinman, 2005); and overall, emotions of fear, nervousness, sadness, and guilt (Reynolds et al., 2008). In a study which compared samples of people in quarantine with control groups, it was observed that psychological distress occurred in $34 \%$ of the population in quarantine, compared to $12 \%$ of the people who had not been isolated (Taylor et al., 2008). Another study which compared quarantined parents and children with a control group found that the prevalence of PTSD in quarantined parents was up to four times higher (28\%) than in non-quarantined parents (6\%) (Sprang \& Silman, 2013).

One of the groups on which lockdowns have been found to have a great impact is health professionals, in whom acute stress, exhaustivity, irritability, insomnia, lack of concentration, and reduced performance in the workplace have been detected (Bai et al., 2004). Another study reported quarantine as a predictor of PTSD among hospital staff as much as three years later (Wu et al., 2009).

In addition, several factors can influence the effect the emergency and quarantine situation have in impacting mental health. The review by Brooks et al. in 2020 highlighted the following stressors: a long period of quarantine (Hawryluck et al., 2004; Reynolds et al., 2008); fear of infection (Bai et al., 2004; Cava et al., 2005; Desclaux et al., 2017; Hawryluck et al., 2004; Reynolds et al., 2008; Robertson et al., 2004); frustration and boredom; supply issues; and inadequate information (Blendon et al., 2004; Braunack-Mayer et al., 2013; Caleo et al., 2018; Cava et al., 2005; DiGiovanni et al., 2004; Pellecchia et al., 2015; Robertson et al., 2004; Wilken et al., 2017). As subsequent stressors, they pointed to financial losses (Maunder, 2004; Reynolds et al., 2008; Wester \& Giesecke, 2019) and the stigma associated with the disease (Cava et al., 2005; Desclaux et al., 2017; DiGiovanni et al., 2004; Hawryluck et al., 2004; Pan et al., 2005; Pellecchia et al., 2015; Reynolds et al., 2008; Robertson et al., 2004; Y. Wang et al., 2011; Wester \& Giesecke, 2019; Wilken et al., 2017).

This same review indicated that being a health worker (Reynolds et al., 2008), and having a previous record of mental health problems (Jeong et al., 2016), was 
associated with greater psychological difficulties during quarantine. Contradictory results were found regarding other variables, such as age, education, or gender identity (Hawryluck et al., 2004; Taylor et al., 2008).

The impact of quarantine due to COVID-19 on perceived clinical and psychosocial variables seems obvious, with a significant number of studies from different countries now available showing the impact of the pandemic on increased clinical symptoms such as anxiety, depression, post-traumatic stress, and even suicides (González-Sanguino et al., 2020; Huang \& Zhao, 2020; Mazza et al., 2020; Pappa et al., 2020; Tanoue et al., 2020; Voitsidis et al., 2020; Wang, Pan, Wan, Tan, Xu, Ho, et al., 2020a; Wang, Pan, Wan, Tan, Xu, McIntyre, et al., 2020b). Furthermore, these studies indicated that being a woman, a student, or presenting physical symptoms or a poor self-rated health status were predictors of a negative psychological impact caused by the situation.

Also of note were an increase in perceived loneliness due to confinement (Banerjee \& Rai, 2020; Losada-Baltar et al., 2020), and an increase in the sense of stigmatization and discrimination associated with COVID-19 (He et al., 2020; Singh \& Subedi, 2020).

Saltzman et al. (2020) note that after a disaster such as a pandemic, social support and community ties play a crucial protective role in mental health recovery. Wang et al. (2018) indicate that common mental health symptoms following pandemics are exacerbated by loneliness and lack of social support. Furthermore, different studies find that social support is a strong predictor of resilience after a disaster, favors positive adaptation (Hall et al., 2010; Saltzman et al., 2018; Xu \& Ou, 2014), and provides protection against the effects of discrimination for different groups (Cristini, Scacchi, Perkins, Santinello, \& Vieno, 2011; Seawell, Cutrona \& Russell, 2014). Even in the context of COVID-19, it has been demonstrated that PSS reduces the psychological impact of this stressful situation (Lei, Huang, Zhang, Yang, Yang, \& Xu, 2020).

Due to the negative consequences and the complexity of the situation resulting from the pandemic, it seems necessary to find methods that can help deal with the situation, such as social support, which empirical evidence has shown has positive effects on health, and serves as a protector in stressful situations (Cohen \& Syme, 1985; Molina et al., 2008).

Despite the growing number of publications reporting similar experiences in different countries, there are few cross-sectional studies that allow direct comparison of responses to the pandemic in different nations. The present study aims to evaluate the different psychological impacts of the crisis and lockdown situations during the first six weeks of emergency measures in samples of the Spanish and Russian populations, in hopes of revealing the possible cultural and social aspects that may be mediating these impacts, with social support as a protective factor.

\section{Methods}

Our study took place from April 13 to April 27 in Spain (the population had been confined for 4-6 weeks at that time), and from May 7 to May 21 in Russia (the population had been confined for 5-7 weeks at that time). A survey developed by the Spanish team was to be completed online using the Google Forms platform, 
with the aim of reaching the maximum population possible (since face-to-face interviews were not possible due to confinement, data had to be collected online). This survey was then translated into English and sent to the Russian team for translation. The study was approved in Spain by the Deontological Commission of the Faculty of Psychology of the Complutense University of Madrid (reference "pr_2019_20_029"), and in Russia by the Ethics Committee of the Faculty of Psychology at Lomonosov Moscow State University (reference No: 2020/37).

The evaluation protocol contained 70 items, and the average time for completion was about seven minutes. It also included a section with information about the research, as well as a consent form authorizing participation in the study and confirming acceptance of the laws regulating protection of personal data [(EU) 2016/679 of the European Parliament and of the Council of 27 April 2016].

\section{Participants}

In Spain, recruitment consisted of sending requests for participation to people in the databases of several different institutions: students and workers in public organizations such as the Complutense University of Madrid and the Chair for Stigma (www.contraelestigma.com), and private organizations such as the company Group 5. These databases are broad enough to provide a reasonable sampling of the Spanish population. To increase the sample size as much as possible, participants were asked to send the survey out by email or through various social networks (Twitter, WhatsApp lists, Facebook, etc.). The percentage of people recruited in this way was small, estimated at less than $5 \%$.

In Russia, the study was conducted using Testograph (“Тестограф"), an online survey platform. Respondents were recruited via social networks (Facebook, VKontakte) and personal e-mail newsletters. The final sample, obtained through the snowball effect, was 1041 people in the Spanish sample, and 743 in the Russian sample, made up of the general population and various specific groups.

Inclusion criteria were: 1) being more than 18 years of age; and 2) living in Spain or Russia during the health emergency created by COVID-19.

\section{Procedure}

The variables and instruments included in the assessment were the following:

Sociodemographic variables: age (subsequently grouped into clusters 18-39, 40-59, 60-80); sex; relationship (single, a couple not sharing a living space, and a couple sharing a living space); educational level (elementary studies, high school, vocational training, university, postgraduate); profession (social-health, education, administration, commercial, and others, such as transport, communications, or tourism); employment situation (working, unemployed, student, retired, unpaid domestic work, other); economic situation (subjective perception from very bad to very good); importance of religious beliefs; and presence of a medical diagnosis (psychiatric and mental health problems, cardiovascular, neurological, respiratory, or other diseases).

Variables related to COVID-19: suffering from symptoms (yes, no); positive or negative diagnosis; hospital admission; existence or not of family members or close relatives who are infected; living with an infected person; perception of the 
information received on the emergency (whether he/she felt he/she had sufficient information, or was overinformed); and work situation (obliged to go to his/her work center or able to work from home).

Psychosocial variables: Loneliness was measured by the 3-item version of the UCLA Loneliness Scale (UCLA-3) (Russell, 1996). The three items in Likert-type format with three response options $(1=$ rarely, $2=$ sometimes, $3=$ often $)$ adressed three dimensions of loneliness: relational connectedness, social connectedness, and self-perceived isolation. A single question on loneliness was also included (Campaign to End Loneliness, 2015): "For the past week, have you been feeling lonely?" Respondents were given the choice of $1=$ hardly ever (less than 1 day); $2=$ sometimes or a small part of the time (1-2 days); 3 = quite a long time (3-4 days); or $4=$ all the time (5-7 days).

Perceived Intersectional Discrimination was evaluated by means of the Intersectional Day-to-Day Discrimination Index (InDI-D) (Scheim \& Bauer, 2019). This scale provides a measure of the intersectional discrimination that can be caused by different conditions: sex, ethnicity, mental health diagnosis, and in this case, the presence of COVID-19. We used the main scale formed by 9 Likert-type items with four response options ( $1=$ never to $4=$ many times). The different questions evaluated the presence of intersectional discrimination from the beginning of the emergency generated by the coronavirus. The higher the score, the more discrimination suffered.

The emotional dimension of Internalized stigma (IS) was evaluated with one item adapted from the Internalized Stigma of Mental Illness (ISMI) (Ritsher et al., 2003), 1-alienation-item-ISMI ("Since the emergency situation generated by the coronavirus, have you felt that the people who aren't in your situation can't understand you?").

Perceived social support (PSS) was evaluated by means of the Multidimensional Scale of Perceived Social Support (MSPSS) (Zimet et al., 1988). The scale, made up of 12 Likert-type items with 7 response alternatives $(1=$ totally disagree to $7=$ totally agree), evaluates the levels of perceived social support, identifying where the support comes from and how it is perceived.

Clinical variables: Depression was assessed through the Patient Health Questionnaire 2 (PHQ-2) (Kroenke et al., 2009). This brief self-report questionnaire addresses the frequency of depressive symptoms. It consists of two Likert-type questions with options ranging from $0=$ never to $3=$ every day. Higher scores indicate more symptomatology, providing a severity range of 0 to 6 , and establishing the cut-off at $>3$ points as a possible case of depression (Muñoz-Navarro et al., 2017). Anxiety was measured through the Generalized Anxiety Disorder Scale (GAD-2) (Spitzer et al., 2006), which includes the first two items of the GAD-7 Likert format, with a maximum score of 6 points. The cut-off point in this case is 3 , above which the possibility of detecting possible cases of anxiety is indicated (Muñoz-Navarro et al., 2017).

\section{Analysis}

Frequencies and percentages were calculated for the socio-demographic variables, and means with their confidence intervals (95\%) were calculated for loneliness, depression, anxiety, discrimination, internalized stigma, and perceived social sup- 
port variables. To compare the values obtained between the two countries, chisquare tests and t-tests were administered respectively. To identify the predictors of mental health disorders, the Enter method was used. The p-values of all tests were adjusted with the Bonferroni correction. Analysis and graphs were developed using $\mathrm{R}$ (v3.5.6) with the nlme package.

\section{Results}

\section{Characteristics of Both Samples: Sociodemographic Composition and Variables Related to COVID-19}

Both samples seemed equivalent in their sociodemographic composition, with a similar proportion of men and women (81\% of women in Spain versus $84 \%$ in Russia; padj $=0.95)$. The average age of the samples was similar: 39.36 in Spain and 38.41 in Russia. Although in other variables the chi-square tests detected differences, these seemed to be minimal, and were due more to an excess of sensitivity due to the size of the sample; there were very similar percentages between both countries in marital status, couple status, employment situation, and age distribution.

The only noteworthy differences were in work situation, with a higher percentage of people working in Russia (72\%) than in Spain (58\%); marital status, with a higher percentage of single people in Spain (52\% in Spain and 27\% in Russia); and perceived economic situation, with $11 \%$ of the Spanish sample and $33 \%$ of the Russian sample considering it to be bad or very bad.

As for the variables of employment during COVID-19, COVID-19 symptoms, COVID-19 diagnosis, and living with someone infected, the two samples were equivalent. Differences in the composition of the two samples were found in the variables COVID-19 relative diagnosis and information received about COVID-19. Table 1 shows the frequencies and percentages for the socio-demographic and Covid-19 related variables.

Table 1

Sociodemographic and Covid-19 related variables of the Spanish and Russian samples

\begin{tabular}{llrrc}
\hline & & Spain (N, \%) & Russia (N, \%) & Padj \\
\hline \multirow{3}{*}{ Sex } & Male & $202(0.19)$ & $116(0.16)$ & \multirow{2}{*}{0.945} \\
& Female & $841(0.81)$ & $615(0.84)$ & \\
\multirow{3}{*}{ Marital status } & Single & $542(0.52)$ & $175(0.27)$ & \\
& Married & $386(0.37)$ & $343(0.52)$ & \\
& Divorced & $82(0.08)$ & $122(0.19)$ & $<0.001^{\star * *}$ \\
& Separate & $28(0.03)$ & $6(0.01)$ & \\
& Widowed & $7(0.01)$ & $13(0.02)$ & \\
\multirow{3}{*}{ Relationship } & Without partner & $265(0.25)$ & $222(0.31)$ & \\
& Couple no sharing & $195(0.19)$ & $105(0.15)$ & 0.140 \\
& Couple sharing & $585(0.56)$ & $386(0.54)$ &
\end{tabular}




\begin{tabular}{|c|c|c|c|c|}
\hline & & Spain (N, \%) & Russia (N, \%) & Padj \\
\hline \multirow{5}{*}{ Education } & Elementary & $15(0.01)$ & $0(0.00)$ & \multirow{5}{*}{$<0.001^{\star * *}$} \\
\hline & High school & $149(0.14)$ & $83(0.11)$ & \\
\hline & Vocational training & $125(0.12)$ & $0(0.0)$ & \\
\hline & University & $401(0.38)$ & $554(0.75)$ & \\
\hline & $\begin{array}{l}\text { Postgraduate } \\
\text { (Master or PhD.) }\end{array}$ & $355(0.34)$ & $59(0.08)$ & \\
\hline \multirow{5}{*}{ Work situation } & Unemployed & $92(0.09)$ & $79(0.11)$ & \multirow{5}{*}{$<0.001^{* * *}$} \\
\hline & Student & $180(0.17)$ & $63(0.09)$ & \\
\hline & Working & $604(0.58)$ & $522(0.72)$ & \\
\hline & Retired & $48(0.05)$ & $36(0.05)$ & \\
\hline & Other & $120(0.11)$ & $27(0.04)$ & \\
\hline \multirow{3}{*}{ Age } & $18-30$ & $306(0.29)$ & $192(0.26)$ & \multirow{3}{*}{$<0.01^{\star *}$} \\
\hline & $31-59$ & $670(0.64)$ & $519(0.71)$ & \\
\hline & $60-80$ & $69(0.07)$ & $20(0.03)$ & \\
\hline \multirow{3}{*}{$\begin{array}{l}\text { Employment during } \\
\text { COVID-19 }\end{array}$} & Non applicable & $427(0.41)$ & $286(0.39)$ & \multirow{3}{*}{1.000} \\
\hline & Face-to-face work & $148(0.14)$ & $129(0.18)$ & \\
\hline & Work from home & $470(0.45)$ & $316(0.43)$ & \\
\hline \multirow{2}{*}{$\begin{array}{l}\text { COVID-19 } \\
\text { symptoms }\end{array}$} & No & $836(0.8)$ & $615(0.84)$ & \multirow{2}{*}{0.438} \\
\hline & Yes & $209(0.2)$ & $116(0.16)$ & \\
\hline \multirow{2}{*}{$\begin{array}{l}\text { COVID-19 } \\
\text { diagnosis }\end{array}$} & No & $1030(0.99)$ & $720(0.98)$ & \multirow{2}{*}{1.000} \\
\hline & Yes & $15(0.01)$ & $11(0.02)$ & \\
\hline \multirow{2}{*}{$\begin{array}{l}\text { COVID-19 relative } \\
\text { diagnosis }\end{array}$} & No & $638(0.61)$ & $585(0.8)$ & \multirow{2}{*}{$<0.001^{\star * *}$} \\
\hline & Yes & $407(0.39)$ & $146(0.2)$ & \\
\hline \multirow{2}{*}{$\begin{array}{l}\text { Living with someone } \\
\text { infected }\end{array}$} & No & $1016(0.97)$ & $718(0.98)$ & \multirow{2}{*}{1.000} \\
\hline & Yes & $29(0.03)$ & $13(0.02)$ & \\
\hline \multirow{3}{*}{$\begin{array}{l}\text { Information received } \\
\text { about COVID-19 }\end{array}$} & Not enough & $184(0.18)$ & $367(0.5)$ & \multirow{3}{*}{$<0.001^{* * *}$} \\
\hline & Good & $594(0.57)$ & $234(0.32)$ & \\
\hline & Overinformed & $267(0.26)$ & $130(0.18)$ & \\
\hline
\end{tabular}

${ }^{*} p<0.05 ;{ }^{* *} p<0.01 ;{ }^{* * *} p<0.001$

\section{Comparison on Clinical and Psychosocial Variables}

The Spanish sample showed higher scores in depressive (PHQ-2) and anxiety symptoms (GAD-2), although these differences were not statistically significant. In relation to the psychosocial variables, the average scores on both the measures 
of loneliness (single item on Loneliness and UCLA-3) and the stigma-related variables (perceived intersectional discrimination, measured by InDI-D, and internalized stigma, measured by ISMI) showed higher scores in the Russian sample. Regarding social support (EMAS), significantly higher scores were found in the Spanish sample overall and in all subscales. Table 2 shows the means and their confidence intervals (95\%) on the clinical and psychosocial variables. These results can also be observed in Figure 1.

Table 2

Means and their confidence intervals (95\%) on clinical and psychosocial variables of the Spanish and Russian sample

\begin{tabular}{lccc}
\hline & Spain & Russia & padj \\
\hline PHQ-2 & $1.81(1.72 ; 1.89)$ & $1.62(1.49 ; 1.75)$ & 0.254 \\
GAD-2 & $1.8(1.7 ; 1.89)$ & $1.77(1.64 ; 1.91)$ & 1.000 \\
UCLA-3 & $4.53(4.43 ; 4.63)$ & $5.06(4.92 ; 5.21)$ & $<0.001^{\star * *}$ \\
Discrimination (InDI-D) & $1.22(1.09 ; 1.34)$ & $2.5(2.28 ; 2.73)$ & $<0.001^{\star * *}$ \\
$\begin{array}{l}\text { Emotional internalized stigma } \\
\text { (1-alienation-item-ISMI) }\end{array}$ & $1.46(1.34 ; 1.49)$ & $1.66(1.7 ; 1.65)$ & $<0.001^{\star * *}$ \\
MSPSS Friends & $23.45(23.15 ; 23.75)$ & $19.41(18.97 ; 19.84)$ & $<0.001^{\star * *}$ \\
MSPSS Family & $23.22(22.9 ; 23.54)$ & $21.37(20.95 ; 21.8)$ & $<0.001^{\star * *}$ \\
MSPSS Significant Others & $23.95(23.62 ; 24.27)$ & $21.05(20.6 ; 21.5)$ & $<0.001^{\star * *}$ \\
Social support (MSPSS Total) & $70.62(69.81 ; 71.42)$ & $61.83(60.68 ; 62.97)$ & $<0.001^{\star * *}$ \\
\hline
\end{tabular}
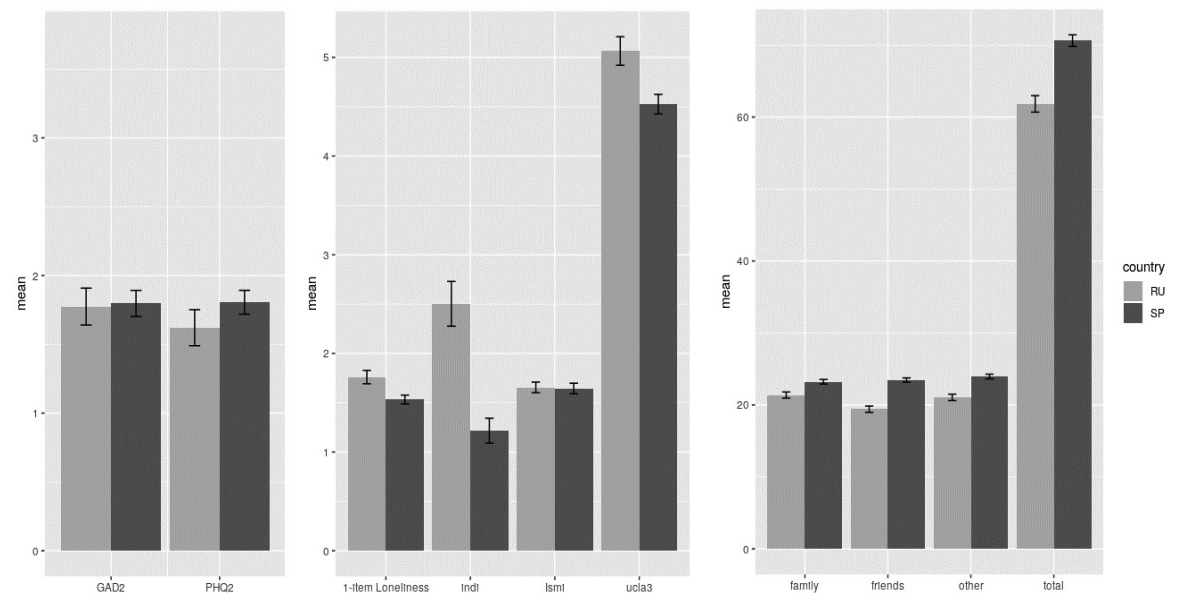

Figure 1. Differences between the Spanish and Russian samples in clinical and psychosocial variables 


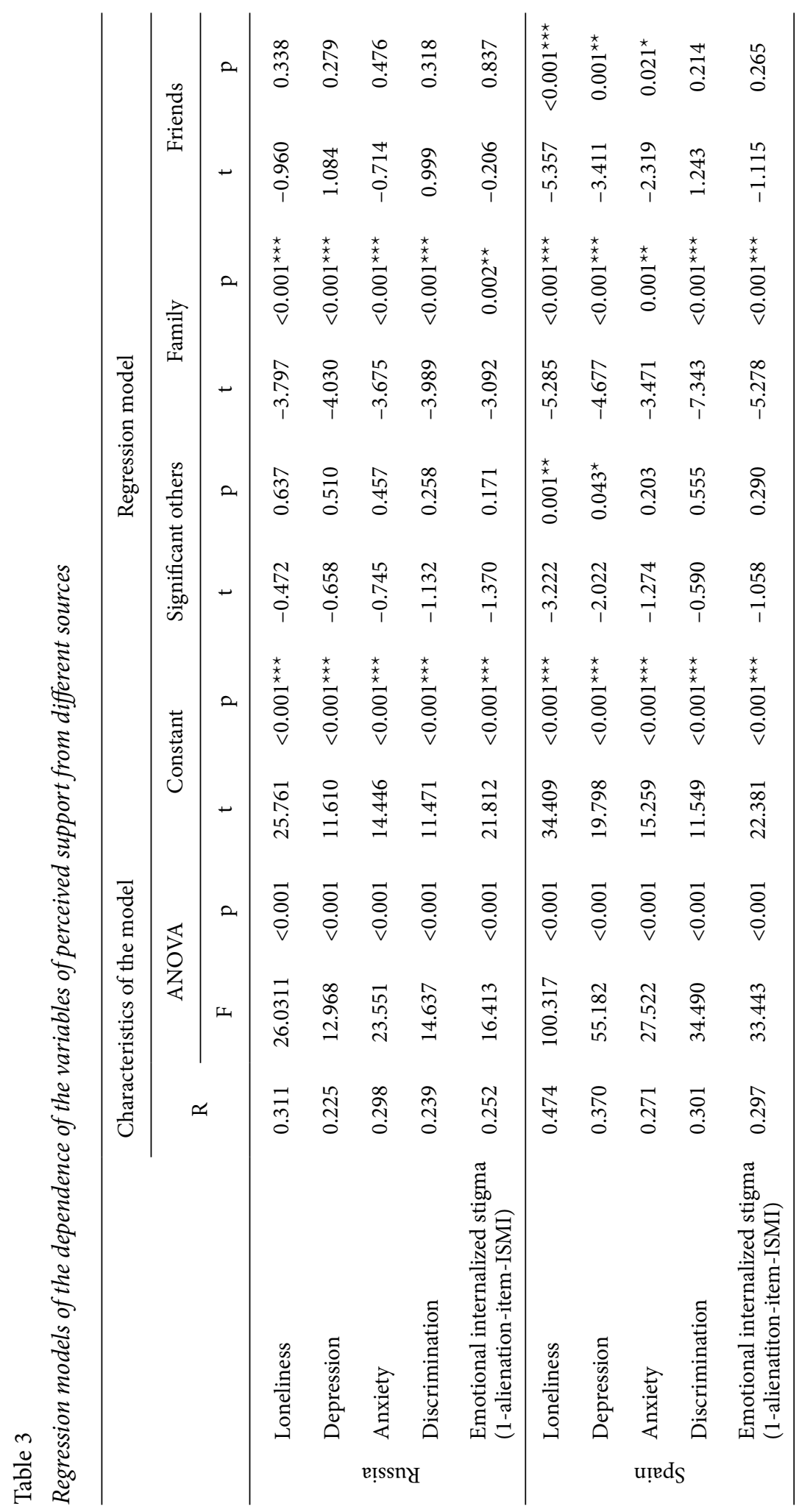




\section{Regression Analysis on the Perceived Social Support}

Using regression analysis (Enter method), we looked at which sources of perceived social support were predictors of lesser loneliness, depression, anxiety, discrimination, and internalized stigma in participants from Spain and Russia. For the Russian sample, the predictor for a reduced rate of depression and anxiety, as well as loneliness, discrimination, and stigmatization was perceived social support from only one of the three possible sources - the family. Perceived support from other sources (friends and significant others) was not significantly related to any of the variables under study.

By contrast, for the Spanish sample, the relationship between perceived social support and the variables under study was more diverse: 1) the predictor of less pronounced loneliness and depression was perceived social support from all three sources: significant others, family, and friends; 2 ) the predictor of less pronounced anxiety was the perceived support from family and friends; 3) perceived social support from the family was a predictor of less pronounced discrimination and stigma; and 4) family support was associated with a decrease in loneliness, depression, anxiety, discrimination, and internalized stigma. These results are shown in Table 3.

\section{Discussion}

This study highlights the consequences of the COVID-19 pandemic on various variables in a way consistent with previous research, which showed the impact of the crisis situation in different countries on increasing symptoms of anxiety or depression (Gonzalez-Sanguino et al., 2020; Wang et al., 2020a; Wang et al., 2020b; Mazza et al., 2020; Pappa et al., 2020; Voitsidis et al., 2020; Tanoue et al., 2020); increasing perceived loneliness (Banerjee \& Rai, 2020; Losada-Baltar et al., 2020); and increasing the appearance of stigmatization (Singh \& Subedi, 2020; He et al., 2020). The results of this cross-cultural study revealed differences in the psychosocial variables between the participants from Spain and Russia during the global crisis associated with the spread of COVID-19 in the first six weeks of the lockdown, as well as with the specifics of social support in this context.

Clinical variables such as depression and anxiety in the two countries did not differ significantly (although they were slightly higher in Spain), so this may indicate that the impact of the pandemic and the response at a clinical level have been similar in both countries. However, this assertion should be made with caution, since our research does not have pre-pandemic measures for comparison. Previous studies suggest that the prevalence and incidence of anxiety and depression were not equivalent in both countries previously, with a slightly higher proportion of the Spanish population exhibiting depressive and anxiety disorders (Institute for Health Metrics and Evaluation - IHME, 2017) than in Russia; this is also consistent with the slightly higher results in the Spanish sample.

The main differences between the two countries were found in the psychosocial variables, with the level of loneliness and stigma-related variables (perceived intersectional discrimination and 1-alienation-item-of internalized stigma) significant- 
ly higher in the Russian sample, and perceived social support from family, friends and others significantly higher in the Spanish respondents.

These results may reflect certain cultural differences between the two countries, which, in times of a crisis, can affect the resources available to cope with the situation. Spain is a country where social relations play a key role, which has strong social networks, and where much attention is paid to family and other interpersonal relationships. These strong interpersonal and intergroup connections can protect an individual from feeling lonely and can prevent the feelings of being discriminated against and stigmatized, thus explaining the lower scores in the loneliness variables and stigma-related variables.

The differences between the two countries in the values of perceived intersectional discrimination could be explained by possible differences between the two countries in their valuations of different races, gender, disability, sexual orientation, or other status. The analysis by Ugidos et al. (2020) on the impact of COVID-19 on intersectional discrimination and stigma, found that the variables that best predict perceived intersectional discrimination and internalized stigma are depression and anxiety, and less family support. These authors note that these results could be explained by the fact that family support is a protective variable, allowing people to feel included in a family nucleus, and thus can buffer the harmful effects of stressful events by providing a sense of acceptance and self-worth, and reducing internalized stigma.

This explanation is also compatible with the results found in the differences in social support, where, significantly, the Spanish population showed it felt more supported by relatives, friends, and other sources.

In both countries, perceived social support acted as a buffer to mitigate the impact of the pandemic and the required containment measures on mental health, although there were differences between the two: in Russia only family support was significant, while in Spain, although family was the main protective source, friends and other sources were also significant protectors against loneliness. Perhaps this is also a sign of differences at the cultural level, where in Russia the family has a more important value and has perhaps been more accessible (higher percentage of married people) than friends in this crisis situation.

On the other hand, other cultural differences that might have been a determining factor in the differences in outcomes would be the respective governments' management of the crisis, with different styles of communication and transmission of information, as well as possible differences in the use and access of new technologies which allow contact with loved ones despite the confinement.

In any case, the results allow us to draw conclusions regarding the crucial role of perceived social support, results consistent with other studies conducted during the pandemic, which showed how social support had a negative relationship with anxiety in students (Cao et al., 2020), and a positive one with increased self-efficacy and quality of sleep among medical staff (Xiao et al., 2020). Additionally, our results highlight the role of family ties in the context of a pandemic and isolation from society regardless of the cultural context, and allow us to assume that those with low levels of perceived family support would become a risk group in the longterm perspective. 


\section{Conclusion}

The present research has allowed us to ascertain the differences in the consequences of the pandemic in a sample of the Russian and Spanish populations. While in both countries the impact at the clinical level seems to be similar, differences are found at the psychosocial level, which may be key, and should determine the response needed to alleviate the effects of the crisis. Social support seems to be a protective factor for our psychological health, with specific cultural characteristics for each country, which must be taken into account as we seek to mitigate the consequences of the crisis.

Given the growing numbers of detected cases of coronavirus infection worldwide and the high degree of uncertainty of the situation, the mental health and well-being of the entire population and individual groups in particular are likely to be at risk for the foreseeable future. Although important short-term results concerning the impact of the pandemic on the mental health of the population in different countries have already been obtained, it is necessary to continue developing research in this direction on a global scale, taking into account the differences in socio-cultural context, in the characteristics of the epidemiological dynamic in individual countries or regions, in the restrictive measures taken, and also in their long-term effects on mental health.

In considering future lines of action to mitigate the loneliness of people in confined situations and increase social support, it should be noted that online technologies could be used to provide networks of social support and a sense of belonging (Armitage and Nellums, 2020). These authors indicate the suitability of training people in the use of digital resources, but also the usefulness of interventions involving more frequent telephone contact with significant people, close relatives, and friends, voluntary organizations or health professionals, or community projects that provide support during confinement. In addition, cognitive-behavioral therapy could administered online to decrease loneliness and improve psychological well-being.

Furthermore, to combat the stigma associated with the COVID-19 pandemic, we recommend being careful in the language used when talking about the disease; avoiding the spread of false news; and taking care to disseminate only precise information related to COVID-19 to the public, thus making it easier for people to request help (IFRC, UNICEF \& WHO, 2020).

\section{Limitations}

The present research has several limitations. First, the type of sampling we used does not ensure that the sample is representative of the population, since groups such as the elderly, sexual and ethnic minorities, or others, were underrepresented. In addition, the type of online survey we used may also have excluded a significant percentage of persons who couldn't have access to new technologies, in addition to lacking the ability to have an expert interviewer ask the person the questions.

Another limitation was the lack of inclusion of some relevant variables, such as whether the participants lived in a rural or urban area; these contexts could have made a significant difference in their perceptions of the pandemic. Finally, it should 
be noted that some of the scales were translated into Russian or Spanish specifically for this research, without being validated or standardized in relation to the samples from these countries.

\section{Acknowledgements}

The part of the study carried out in Russia was supported by the Russian Foundation of Basic Research (Project No. 20-04-60174). Our thanks to the extraordinary anti-stigma chair Group - 5 - UCM that helped to recruit the Spanish sample.

\section{References}

Armitage, R., \& Nellums, L.B. (2020). COVID-19 and the consequences of isolating the elderly. The Lancet Public Health, 5. https://doi.org/10.1016/S2468-2667(20)30061-X

Bai, Y.M., Lin, C.C., Lin, C.Y., Chen, J.Y., Chue, C.M., \& Chou, P. (2004). Survey of stress reactions among health care workers involved with the SARS outbreak. Psychiatric Services. https://doi. org/10.1176/appi.ps.55.9.1055

Banerjee, D., \& Rai, M. (2020). Social isolation in COVID-19: The impact of loneliness. In The International Journal of Social Psychiatry (p. 20764020922269). https://doi. org/10.1177/0020764020922269

Blendon, R.J., Benson, J.M., DesRoches, C.M., Raleigh, E., \& Taylor-Clark, K. (2004). The Public's Response to Severe Acute Respiratory Syndrome in Toronto and the United States. Clinical Infectious Diseases, 38(7), 925-931. https://doi.org/10.1086/382355

Braunack-Mayer, A., Tooher, R., Collins, J.E., Street, J.M., \& Marshall, H. (2013). Understanding the school community's response to school closures during the H1N1 2009 influenza pandemic. BMC Public Health. https://doi.org/10.1186/1471-2458-13-344

Caleo, G., Duncombe, J., Jephcott, F., Lokuge, K., Mills, C., Looijen, E., ... Greig, J. (2018). The factors affecting household transmission dynamics and community compliance with Ebola control measures: A mixed-methods study in a rural village in Sierra Leone. BMC Public Health, 18(1), 248. https://doi.org/10.1186/s12889-018-5158-6

Cao, W., Fang, Z., Hou, G., Han, M., Xu, X., Dong, J., \& Zheng, J. (2020). The psychological impact of the COVID-19 epidemic on college students in China. Psychiatry Research, 287, 112934. https:// doi.org/10.1016/j.psychres.2020.112934

Cava, M.A., Fay, K.E., Beanlands, H.J., McCay, E.A., \& Wignall, R. (2005). The experience of quarantine for individuals affected by SARS in Toronto. Public Health Nursing, 22(5), 398-406. https:// doi.org/10.1111/j.0737-1209.2005.220504.x

Cohen, S.E., \& Syme, S.L. (1985). Social Support and Health. Academic Press.

Cristini, F., Scacchi, L., Perkins, D.D., Santinello, M., \& Vieno, A. (2011). The influence of discrimination on immigrant adolescents' depressive symptoms: What buffers its detrimental effects? Psychosocial Intervention, 20(3), 243-253. https://doi.org/10.5093/in2011v20n3a2

Desclaux, A., Badji, D., Ndione, A.G., \& Sow, K. (2017). Accepted monitoring or endured quarantine? Ebola contacts' perceptions in Senegal. Social Science and Medicine, 178, 38-45. https://doi. org/10.1016/j.socscimed.2017.02.009

DiGiovanni, C., Conley, J., Chiu, D., \& Zaborski, J. (2004). Factors influencing compliance with quarantine in Toronto during the 2003 SARS outbreak. Biosecurity and Bioterrorism: Biodefense Strategy, Practice, and Science, 2(4), 265-272. https://doi.org/10.1089/bsp.2004.2.265

Federal Service for the Oversight of Consumer Protection and Welfare (2020). Retrieved from https:// www.rospotrebnadzor.ru/en/

González-Sanguino, C., Ausín, B., Ángel Castellanos, M., Saiz, J., López-Gómez, A., Ugidos, C., \& Muñoz, M. (2020). Mental Health Consequences during the Initial Stage of the 2020 Coronavirus Pandemic (COVID-19) in Spain. Brain, Behavior, and Immunity. https://doi.org/10.1016/j. bbi.2020.05.040

Hall, B.J., Hobfoll, S.E., Canetti, D., Johnson, R.J., Palmieri, P.A., \& Galea, S. (2010). Exploring the association between posttraumatic growth and PTSD: A national study of Jews and Arabs follow- 
ing the 2006 Israeli-Hezbollah war. Journal of Nervous and Mental Disease, 198, 180-186. http:// dx.doi.org/10.1097/NMD.0b013e3181d1411b

Hawryluck, L., Gold, W.L., Robinson, S., Pogorski, S., Galea, S., \& Styra, R. (2004). SARS control and psychological effects of quarantine, Toronto, Canada. Emerging Infectious Diseases, 10(7), 1206-1212. https://doi.org/10.3201/eid1007.030703

He, J., He, L., Zhou, W., Nie, X., \& He, M. (2020). Discrimination and Social Exclusion in the Outbreak of COVID-19. International Journal of Environmental Research and Public Health, 17(8), 2933. https://doi.org/10.3390/ijerph17082933

Health Ministry, Government of Spain (2020). Retrieved from https://www.mscbs.gob.es/en/profesionales/saludPublica/ccayes/alertasActual/nCov-China/situacionActual.htm

Huang, Y., \& Zhao, N. (2020). Generalized anxiety disorder, depressive symptoms and sleep quality during COVID-19 outbreak in China: a web-based cross-sectional survey. Psychiatry Research, 288, 112954. https://doi.org/https://doi.org/10.1016/j.psychres.2020.112954

IFRC, UNICEF \& WHO. (2020). Social stigma associated with COVID-19. A guide to preventing and addressing social stigma. Retrieved from https://www.who.int/docs/default-source/coronaviruse/ covid19-stigma-guide.pdf?sfvrsn = 226180f4_2

Institute for Health Metrics and Evaluation (IHME) (2017). Retrieved from http://www.healthdata. org/

Jeong, H., Yim, H.W., Song, Y.J., Ki, M., Min, J.A., Cho, J., \& Chae, J.H. (2016). Mental health status of people isolated due to Middle East Respiratory Syndrome. Epidemiology and Health, 38, e2016048. https://doi.org/10.4178/epih.e2016048

Kroenke, K., Spitzer, R.L., Williams, J.B.W., \& Löwe, B. (2009). An ultra-brief screening scale for anxiety and depression: The PHQ-4. Psychosomatics, 50(6), 613-621. https://doi.org/10.1176/ appi.psy.50.6.613

Lee, S., Chan, L.Y.Y., Chau, A.M.Y., Kwok, K.P.S., \& Kleinman, A. (2005). The experience of SARSrelated stigma at Amoy Gardens. Social Science and Medicine, 61(9), 2038-2046. https://doi. org/10.1016/j.socscimed.2005.04.010

Liu, X., Kakade, M., Fuller, C.J., Fan, B., Fang, Y., Kong, J., ... Wu, P. (2012). Depression after exposure to stressful events: Lessons learned from the severe acute respiratory syndrome epidemic. Comprehensive Psychiatry, 53(1), 15-23. https://doi.org/10.1016/j.comppsych.2011.02.003

Losada-Baltar, A., Jiménez-Gonzalo, L., Gallego-Alberto, L., Pedroso-Chaparro, M.D.S., Fernandes-Pires, J., \& Márquez-González, M. (2020). "We’re staying at home." Association of selfperceptions of aging, personal and family resources, and loneliness with psychological distress during the lock-down period of COVID-19. The Journals of Gerontology. Series B, Psychological Sciences and Social Sciences. https://doi.org/10.1093/geronb/gbaa048

Marjanovic, Z., Greenglass, E.R., \& Coffey, S. (2007). The relevance of psychosocial variables and working conditions in predicting nurses' coping strategies during the SARS crisis: An online questionnaire survey. International Journal of Nursing Studies, 44(6), 991-998. https://doi. org/10.1016/j.ijnurstu.2006.02.012

Maunder, R. (2004). The experience of the 2003 SARS outbreak as a traumatic stress among frontline healthcare workers in Toronto: Lessons learned. Philosophical Transactions of the Royal Society B: Biological Sciences (Vol. 359, pp. 1117-1125). Royal Society. https://doi.org/10.1098/ rstb.2004.1483

Mazza, C., Ricci, E., Biondi, S., Colasanti, M., Ferracuti, S., Napoli, C., \& Roma, P. (2020). A Nationwide Survey of Psychological Distress among Italian People during the COVID-19 Pandemic: Immediate Psychological Responses and Associated Factors. In International Journal of Environmental Research and Public Health, 17 (9). https://doi.org/10.3390/ijerph17093165

Mihashi, M., Otsubo, Y., Yinjuan, X., Nagatomi, K., Hoshiko, M., \& Ishitake, T. (2009). Predictive Factors of Psychological Disorder Development During Recovery Following SARS Outbreak. Health Psychology, 28(1), 91-100. https://doi.org/10.1037/a0013674

Molina, J.L., Fernandez, R., Llopis, J., \& McCarty, C. (2008). El Apoyo Social en Situaciones de Crisis: Un estudio de caso desde la perspectiva de las redes personales. Portularia, 8(1), 61-76.

Muñoz-Navarro, R., Cano-Vindel, A., Medrano, L.A., Schmitz, F., Ruiz-Rodríguez, P., Abellán-Maeso, C., ... Hermosilla-Pasamar, A.M. (2017). Utility of the PHQ-9 to identify major depressive dis- 
order in adult patients in Spanish primary care centres. BMC Psychiatry, 17(1), 291. https://doi. org/10.1186/s12888-017-1450-8

Pan, P. J.D., Chang, S.H., \& Yu, Y.Y. (2005). A support group for home-quarantined college students exposed to SARS: Learning from practice. Journal for Specialists in Group Work, 30(4), 363-374. https://doi.org/10.1080/01933920500186951

Pappa, S., Ntella, V., Giannakas, T., Giannakoulis, V.G., Papoutsi, E., \& Katsaounou, P. (2020). Prevalence of depression, anxiety, and insomnia among healthcare workers during the COVID-19 pandemic: A systematic review and meta-analysis. Brain, Behavior, and Immunity. https://doi. org/10.1016/j.bbi.2020.05.026

Pellecchia, U., Crestani, R., Decroo, T., Van den Bergh, R., \& Al-Kourdi, Y. (2015). Social Consequences of Ebola Containment Measures in Liberia. PLOS ONE, 10(12), e0143036. https://doi. org/10.1371/journal.pone.0143036

Reynolds, D.L., Garay, J.R., Deamond, S.L., Moran, M.K., Gold, W., \& Styra, R. (2008). Understanding, compliance and psychological impact of the SARS quarantine experience. Epidemiology and Infection, 136(7), 997-1007. https://doi.org/10.1017/S0950268807009156

Ritsher, J.B., Otilingam, P.G., \& Grajales, M. (2003). Internalized stigma of mental illness: psychometric properties of a new measure. Psychiatry Research, 121(1), 31-49. https://doi.org/10.1016/j. psychres.2003.08.008

Robertson, E., Hershenfield, K., Grace, S.L., \& Stewart, D.E. (2004). The psychosocial effects of being quarantined following exposure to SARS: A qualitative study of Toronto health care workers. Canadian Journal of Psychiatry, 49(6), 403-407. https://doi.org/10.1177/070674370404900612

Russell, D.W. (1996). UCLA Loneliness Scale (Version 3): Reliability, validity, and factor structure. Journal of Personality Assessment, 66(1), 20-40. https://doi.org/10.1207/s15327752jpa6601_2

Saltzman, L.Y., Hansel, T.C., \& Bordnick, P.S. (2020). Loneliness, isolation, and social support factors in post-COVID-19 mental health. Psychological Trauma: Theory, Research, Practice and Policy, 12(S1), S55-S57. https://doi.org/10.1037/tra0000703.

Saltzman, L.Y., Pat-Horenczyk, R., Lombe, M., Weltman, A., Ziv, Y., McNamara, T., ... Brom, D. (2018). Post-combat adaptation: Improving social support and reaching constructive growth. Anxiety, Stress \& Coping: An International Journal, 31, 418-430. http://dx.doi.org/10 $.1080 / 10615806.2018 .1454740$

Scheim, A.I., \& Bauer, G.R. (2019). The Intersectional Discrimination Index: Development and validation of measures of self-reported enacted and anticipated discrimination for intercategorical analysis. Social Science and Medicine, 226, 225-235. https://doi.org/10.1016/j.socscimed.2018.12.016

Seawell, A.H., Cutrona, C.E., \& Russell, D.W. (2014). The effects of general social support and social support for racial discrimination on African American women's well-being. Journal of Black Psychology, 40(1), 3-26. https://doi.org/10.1177/0095798412469227

Singh, R., \& Subedi, M. (2020). COVID-19 and Stigma: Social discrimination towards frontline healthcare providers and COVID-19 recovered patients in Nepal. Asian Journal of Psychiatry. https://doi.org/10.1016/j.ajp.2020.102222

Spitzer, R.L., Kroenke, K., Williams, J.B.W., \& Löwe, B. (2006). A brief measure for assessing generalized anxiety disorder: The GAD-7. Archives of Internal Medicine, 166(10), 1092-1097. https://doi. org/10.1001/archinte.166.10.1092

Sprang, G., \& Silman, M. (2013). Posttraumatic stress disorder in parents and youth after healthrelated disasters. Disaster Medicine and Public Health Preparedness, 7(1), 105-110. https://doi. org/10.1017/dmp.2013.22

Tanoue, Y., Nomura, S., Yoneoka, D., Kawashima, T., Eguchi, A., Shi, S., ... Miyata, H. (2020). Mental health of family, friends, and co-workers of COVID-19 patients in Japan. Psychiatry Research, 291, 113067. https://doi.org/https://doi.org/10.1016/j.psychres.2020.113067

Taylor, M.R., Agho, K.E., Stevens, G.J., \& Raphael, B. (2008). Factors influencing psychological distress during a disease epidemic: Data from Australia's first outbreak of equine influenza. BMC Public Health, 8(1), 347. https://doi.org/10.1186/1471-2458-8-347

Ugidos, C., López-Gómez, A., González-Sanguino, C., Castellanos, M.Á., Saiz, J., Ausín, B., \& Muñoz, M. (2020). Evolution of intersectional perceived discrimination and internalized stigma during 
COVID-19 lockdown among the general population in Spain. International Journal of Social Psychiatry.

Voitsidis, P., Gliatas, I., Bairachtari, V., Papadopoulou, K., Papageorgiou, G., Parlapani, E., ... Diakogiannis, I. (2020). Insomnia during the COVID-19 pandemic in a Greek population. Psychiatry Research, 289, 113076. https://doi.org/https://doi.org/10.1016/j.psychres.2020.113076

Wang, J., Mann, F., Lloyd-Evans, B., Ma, R., \& Johnson, S. (2018). Associations between loneliness and perceived social support and outcomes of mental health problems: A systematic review. BMC Psychiatry, 18, 156. http://dx.doi.org/10.1186/s12888-018-1736-5

Wang, Y., Xu, B., Zhao, G., Cao, R., He, X., \& Fu, S. (2011). Is quarantine related to immediate negative psychological consequences during the $2009 \mathrm{H} 1 \mathrm{N1}$ epidemic? General Hospital Psychiatry, 33(1), 75-77. https://doi.org/10.1016/j.genhosppsych.2010.11.001

Wang, C., Pan, R., Wan, X., Tan, Y., Xu, L., Ho, C.S., \& Ho, R.C. (2020a). Immediate Psychological Responses and Associated Factors during the Initial Stage of the 2019 Coronavirus Disease (COVID-19) Epidemic among the General Population in China. International Journal of Environmental Research and Public Health, 17(5), 1729. https://doi.org/10.3390/ijerph17051729

Wang, C., Pan, R., Wan, X., Tan, Y., Xu, L., McIntyre, R.S., ... Ho, C. (2020b). A longitudinal study on the mental health of general population during the COVID-19 epidemic in China. Brain, Behavior, and Immunity. https://doi.org/10.1016/j.bbi.2020.04.028

Wester, M., \& Giesecke, J. (2019). Ebola and healthcare worker stigma. Scandinavian Journal of Public Health, 47(2), 99-104. https://doi.org/10.1177/1403494817753450

Wu, P., Fang, Y., Guan, Z., Fan, B., Kong, J., Yao, Z., ... Hoven, C.W. (2009). The psychological impact of the SARS epidemic on hospital employees in China: Exposure, risk perception, and altruistic acceptance of risk. Canadian Journal of Psychiatry, 54(5), 302-311. https://doi. org/10.1177/070674370905400504

Xiao, H., Zhang, Y., Kong, D., Li, S., \& Yang, N. (2020). The Effects of Social Support on Sleep Quality of Medical Staff Treating Patients with Coronavirus Disease 2019 (COVID-19) in January and February 2020 in China. Medical Science Monitor: International Medical Journal of Experimental and Clinical Research, 26, e923549-e923549. https://doi.org/10.12659/MSM.923921

$\mathrm{Xu}$, J., \& Ou, L. (2014). Resilience and quality of life among Wenchuan earthquake survivors: The mediating role of social support. Public Health, 128, 430-437. http://dx.doi.org/10.1016/j. puhe.2014.03.002

Yoon, M.K., Kim, S.Y., Ko, H.S., \& Lee, M.S. (2016). System effectiveness of detection, brief intervention and refer to treatment for the people with post-traumatic emotional distress by MERS: A case report of community-based proactive intervention in South Korea. International Journal of Mental Health Systems, 10(1), 51. https://doi.org/10.1186/s13033-016-0083-5

Zimet, G.D., Dahlem, N.W., Zimet, S.G., \& Farley, G.K. (1988). The Multidimensional Scale of Perceived Social Support. Journal of Personality Assessment, 52(1), 30-41. https://doi.org/10.1207/ s15327752jpa5201_2

Original manuscript received July 27, 2020

Revised manuscript accepted November 15, 2020

First published online December 30, 2020

To cite this article: Ausín, B., Castellanos, M.A., González-Sanguino, C., Vakhantseva, O.V., Almazova, O.V., Shaigerova, L.A., Dolgikh, A.G., Muñoz, M. (2020). The Psychological Impact of Six Weeks of Lockdown as a Consequence of COVID-19 and the Importance of Social Support: A Cross-Cultural Study Comparing Spanish and Russian Populations. Psychology in Russia: State of the Art, 13(4), 89-105. DOI: 10.11621/pir.2020.0406 